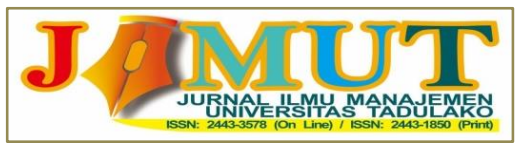

Vol. 7, No 1, Januari 2021, 012-020

\title{
PENGARUH PENGALAMAN KONSUMEN TERHADAP LOYALITAS MAHASISWA UNIVERSITAS TADULAKO MENGGUNAKAN KOSMETIK BEDAK MARCKS
}

\author{
Miftah Aulia \\ Wahyuningsih \\ Program Studi Strata 1, Manajemen, Fakultas Ekonomi dan Bisnis, Universitas Tadulako \\ Email: auliamiftah010@gmail.com; ayu_wningsih@yahoo.com
}

\begin{abstract}
The research aims to determine the effect of the consumer experience consisting of sensory experience, emotional experience, and social experience of the student loyalty Faculty of Economics Tadulako University uses Marcks powder Cosmetics in Palu City. This research Data is collected through the method of spreading questionnaires to 90 respondents using the accidental sampling technique. To find out the extent of the impact of the experience on student loyalty then, a double linear regression analysis is used. The results show that the consumer experience of sensory experience, emotional experience, and social experience belongs to good category. Based on partial test results, sensory experience, emotional experience, and social experience have a significant effect on the student loyalty Faculty of Economics Tadulako University uses Marcks powder cosmetics in Palu city. Simultaneously the consumer experience has a significant effect on the student loyalty Faculty of Economics Tadulako University use Marcks powder Cosmetics in Palu city through experience on sensory, emotional, and social factors
\end{abstract}

Keywords, Consumer Experience, Sensory Experience, Emotional Experience, Social Experience, Consumer Loyality.

\begin{abstract}
Abstrak
Penelitian ini bertujuan untuk mengetahui pengaruh pengalaman konsumen yang terdiri dari pengalaman sensori, pengalaman emosional, dan pengalamsan sosial terhadap loyalitas mahasiswa Fakultas Ekonomi Universitas Tadulako menggunakan kosmetik Bedak Marcks di Kota Palu. Data penelitian ini dikumpulkan melalui metode penyebaran kuesioner terhadap 90 responden dengan menggunakan teknik accidental sampling. Untuk mengetahui sejauh mana pengaruh pengalaman kosumen terhadap loyalitas mahasiswa maka, digunakan analisis regresi linier berganda. Hasil penelitian menunjukan bahwa pengalaman konsumen yang terdiri dari pengalaman sensori, pengalaman emosional, dan pengalaman sosial termasuk dalam kategori baik. Berdasarkan hasil uji secara parsial, pengalaman sensori, pengalaman emosional, dan pengalaman sosial memiliki pengaruh secara signifikan terhadap loyalitas mahasiswa Fakultas Ekonomi Universitas Tadulako menggunakan kosmetik Bedak Marcks di Kota Palu. Secara simultan pengalaman konsumen memiliki pengaruh secara signifikan terhadap loyalitas mahasiswa Fakultas Ekonomi Universitas Tadulako menggunakan kosmetik Bedak Marcks di Kota Palu melalui pengalaman pada faktor-faktor sensori, emosional, dan sosial.
\end{abstract}

Kata Kunci, Pengalaman Konsumen, Pengalaman Sensori, Pengalaman Emosional, Pengalaman Sosial dan Loyalitas Mahasiswa.

\section{PENDAHULUAN}

Konsumen dihadapkan pada berbagai pilihan dalam mengkonsumsi suatu produk untuk memenuhi keperluan sehari-harinya. Hal tersebut didukung dengan adanya kemajuan teknologi dan informasi, serta kemajuan industri yang begitu laju. Kosmetik adalah satu diantara industri yang menghadapi 
perkembangan yang sangat pesat. Industri kosmetik Nasional mencatatkan progres $20 \%$ atau empat kali lipat dari pertumbuhan ekonomi Nasional pada tahun 2017. Kementerian Perindustrian telah menaruh industri kosmetik sebagai sektor unggulan sebagaimana tertuang dalam Rencana Induk Pembangunan Industri Nasional (RIPIN) tahun 2015-2035 (Investor Daily. 20/03/2018).

Berdasarkan data yang telah dikemukakan oleh RIPIN maka dapat dipastikan bahwa peningkatan produksi kosmetik terjadi karena banyaknya permintaan dari konsumen. Melonjaknya permintaan dari pasar domestik dan ekspor seiring tren masyarakat yang mulai memperhatikan produk perawatan tubuh juga penunjang penampilan telah menjadikan kosmetik sebagai kebutuhan primer mereka. Meningkatnya minat konsumen terhadap kosmetik memberikan dampak bagi para pebisnis untuk membuka usahanya dibidang bisnis produk komestik.

Mengembangkan sebuah usaha produk kosmetik pebisnis dituntut untuk menciptakan suatu produk kosmetik yang sesuai dengan kebutuhan konsumen yang berbeda-beda. Maksud lain para pebisnis harus bisa menciptakan sebuah ide yang berbeda agar konsumen memiliki pengalaman yang berkesan dan selalu mengingat produk maupun jasa yang ditawarkan tersebut. Sebuah produk harus mampu membangkitkan sensasi dan pengalaman yang baru untuk menimbulkan minat beli pada calon konsumennya.

Pengalaman Konsumen menjadi semacam perangkat bagi perusahaan dalam meningkatkan penjualannya. Menurut Digital Marketing Trends 2016, pengalaman konsumen adalah satu hal terpenting yang bisa menentukan kemajuan bisnis. Kartajaya (2006:95) mengemukakan bahwa saat ini banyak pelanggan yang karena semakin canggih, pelanggan menjadi tidak hanya butuh sebuah servis atau produk berkualitas tinggi, melainkan juga suatu experience yang positif, yang secara emosional sangat menyentuh dan memorable. Pengalaman memberikan memori tersendiri bagi konsumen.

Menurut pandangan Schmitt (1999) bahwa pengalaman yang didapatkan konsumen dibagi menjadi: pengalaman sensori, pengalaman emosional dan pengalaman sosial. Pengalaman sensori refleks dapat mempengaruhi panca indra konsumen. Menciptakan kesan yang positif kepada konsumen merupakan pokok keberhasilan pengalaman sensori. Alamiahnya dengan pengalaman konsumen yang baik dapat memberikan keuntungan jalinan yang makin erat antara perusahaan dan pelanggan, dengan begitu timbulah rasa percaya dari pelanggan pada perusahaan yang menawarkan produk maupun jasanya. Hal itu biasa disebut dengan kepuasaan pelanggan. Pelanggan yang merasa puas akan menumbuhkan rasa percayanya pada perusahaan tersebut dan kemudian terciptalah kesetian dan hingga pada akhirnya hidup dan matinya hanya menggunakan produk dari perusahaan tersebut.

Loyalitas konsumen pada suatu produk dapat dilihat dari keseriusan dan bertahannya konsumen tersebut dalam melakukan pembelian yang berulang. Salah satu jenis produk kosmetik yang terus eksis dari dulu hingga sekarang ialah Bedak Marcks. Produk kosmetik Bedak Marcks dapat bertahan karena Bedak Marcks mampu menawarkan harga yang terjangkau bagi para konsumennya, khususnya para mahasiswa yang menginginkan harga murah dengan kualitas terbaik. Mempercantik diri dengan budget yang terjangkau salah satu hal urgent bagi kalangan wanita termaasuk mahasiswi Fakultas Ekonomi Universitas Tadulako. Beberapa mahasiswa benar-benar telah merasakan pengalaman dari menggunakan produk Bedak Marcks ini.

Sampai saat ini eksistensi Bedak Marcks dikalangan milenial terus tumbuh seiring berjalannya waktu. Khususnya para mahasiswi yang menginginkan kulit wajah yang cerah dan bersih tetapi mencari harga yang tentunya ekonomis bagi mereka. Bedak Marcks adalah jawabannya. Tidak sedikit orang yang telah menggunakan produk Bedak Marcks dan tidak bisa dipungkiri lagi dari pengalaman menggunakan produk itulah yang mem buat mahasiswa ingin tetap terus setia dan bertahan pada produk Bedak Marcks.

Fakultas Ekonomi adalah salah satu Fakultas yang memiliki mahasiswa yang jumlahnya cukup banyak di Universitas Tadulako. Adapun jumlah keseluruhan mahasiwa (aktif) 4.578 orang yang tersebar ditiga program studi yaitu: Jurusan Pembangunan berjumlah 1.575, Manajemen berjumlah 


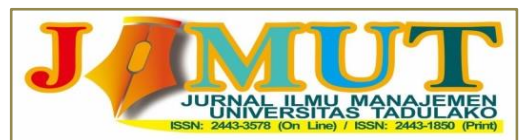

Vol. 7, No 1, Januari 2021, 012-020

1.626 dan Akuntansi berjumlah 1.378. Banyaknya jumlah mahasiswa Fakultas Ekonomi menunjukan bahwa animo dan minat calon-calon mahasiswa baru sampai saat ini masih cukup besar untuk melanjutkan studinya di Fakultas tersebut. Mengingat Bedak Marcks telah menyebar dan digunakan oleh berbagai kalangan termasuk mahasiswa karena kualitasnya cukup bagus dan harganya dapat dijangkau oleh mahasiswa maka penelitian ini berusaha untuk mengetahui apakah ada pengaruh pengalaman konsumen yang terbagi menjadi: pengalaman sensori, pengalaman emosional, dan pengalaman sosial terhadap loyalitas mahasiswa Fakultas Ekonomi Universitas Tadulako menggunakan kosmetik Bedak Marcks di Kota Palu.

\section{KAJIAN LITERATUR DAN PENGEMBANGAN HIPOTESIS}

Smilansky (2009:1) menyatakan bahwa people talk about experience every day because life is ultimately an amalgamation of daily experience. Experience are real. They are true life. Sedangkan Schmitt (1999:60) mendefinisikan experience adalah kejadian-kejadian yang terjadi sebagai tanggapan stimulasi atau rangsangan, contohnya sebagaimana diciptakan oleh usaha-usaha sebelum dan sesudah pembelian. Pengalaman seringkali disebut hasil dari observasi langsung dan atau partisipasi dari kegiatan-kegiatan, baik merupakan kenyataan, angan-angan, maupun virtual

Menurut Meyer dan Schwager (2007) mendefinisikan pengalaman konsumen sebagai respon internal dan subyektif yang dimiliki konsumen terhadap kontak langsung maupun tidak langsung dengan sebuah perusahaan. Kontak langsung umumnya terjadi pada saat pembelian, penggunaan, dan pelayanan

Schmitt (1999) berpendapat bahwa pengalaman yang didapatkan konsumen dibagi menjadi:

1. Pengalaman sensori

Pengalaman sensori adalah usaha untuk menciptakan pengalaman yang berkaitan dengan panca indra, meliputi penglihatan, suara, bau, rasa, dan sentuhan. Pengalaman sensori dirasakan oleh konsumen secara langsung dan mempengaruhi penglihatan, pendengaran, perasa, penciuman, dan sentuhan. Memberikan kesan yang positif terhadap diri konsumen merupakan kunci keberhasilan pengalaman sensori.

2. Pengalaman emosional

Menurut Kartajaya (2004:166) pengalaman emosional timbul karena adanya interaksi yang membangkitkan emosi, baik emosi yang meningkatkan prestige maupun emosi yang memperlihatkan indentitas ekspresi manusia. Emosi lebih kuat dibandingkan dengan suasana hati dan merupakan pernyataan affective dari stimulus yang efektif..

3. Pengalaman sosial.

Menurut Kartajaya (2006:230) bahwa manusia adalah bagian dari kelompok sosial tertentu, karena itu buatlah supaya mereka bangga dan bisa merasa diterima dikomunitasnya. Manusia membutuhkan pengalaman sosial dalam mempelajari berbagai aspek kehidupan dalam hal ini para pengguna Bedak Marcks dapat saling bertukar informasi atau pengalaman mereka dalam mengkonsumsi Bedak Marcks.

Customer loyalty atau loyalitas konsumen menurut Amin Widjaja Tunggal (2008:6) adalah kelekatan pelanggan pada suatu merek, pabrikan, pemberi jasa, atau entitas lain berdasarkan sikap yang menguntungkan dan tanggapan yang baik, seperti pembelian ulang. Pentingnya loyalitas terhadap kelangsungan hidup perusahaan maka perusahaan harus secara kontinyu menjaga dan meningkatkan loyalitas dari para pelanggannya, oleh karena itu untuk membangun loyalitas pelanggan, perusahaan harus memiliki hubungan yang baik dengan pelanggan sehingga perusahaan dapat lebih memahami akan kebutuhan, keinginan dan harapan-harapan para pelanggannya. 


\section{Hubungan antara Pengalaman Konsumen dengan Loyalitas}

Tiap perusahaan memiliki suatu cara dalam menciptakan sebuah strategi untuk menarik konsmen bukan hanya sekedar berkunjung akan tetapi bagaimana cara perusahaan tersebut menciptakan sesuatu hal yang membekas baik dibenak konsumen. Mempertahankan konsumen agar tetap loyal dibutuhkan strategi yang tidak hanya memfokuskan pada kualitas tetapi juga bisa menciptakan pengalaman konsumen yang baik. Pengalaman yang terbentuk dalam diri konsumen menjadi faktor penentu yang signifikan terhadap berkunjungnya kembali konsumen pada perusahaan tersebut.

Ehret (2008) mengembangkan model yang menghubungkan antara pengalaman konsumen, loyalitas dan word of mouth. Pengalaman konsumen yang baik akan menghasilkan loyalitas dan word of mouth, dimana loyalitas tetap menjaga konsumen, sedangkan word of mouth akan berguna dalam ekspansi dan akuisi pelanggan baru.

Pada dasarnya pengalaman konsumen adalah penciptaan kepuasan konsumen terhadap pengalaman yang telah dia dapatkan dari suatu perusahaan. Jadi, titik bertumpu kepada produk akhir dari suatu produk atau pelayanan, oleh karena itu, pengalaman konsumen adalah soal memahami gaya hidup konsumen (mahasiswa) dan melebarkan pandangan pemasar dari produk ke proses konsumsi. Evaluasi pengalaman konsumen tergantung pada perbandingan antara harapan konsumen dan kinerja perusahaan. Apabila harapan konsumen dapat terpenuhi dengan baik tentunya konsumen akan merasa puas dan perlahan loyalitas konsumen pun akan terbentuk.

\section{Hipotesis}

A: Pengalaman konsumen yang terdiri dari variabel pengalaman sensori, variabel pengalaman emosional, dan variabel pengalaman sosial secara serempak berpengaruh signifikan terhadap loyalitas mahasiswa Fakultas Ekonomi Universitas Tadulako menggunakan kosmetik Bedak Marcks di Kota Palu.

B: Apakah variabel pengalaman sensori secara parsial berpengaruh signifikan terhadap loyalitas mahasiswa Fakultas Ekonomi Universitas Tadulako menggunakan kosmetik Bedak Marcks di Kota Palu.

C: Apakah variabel pengalaman emosional secara parsial berpengaruh signifikan terhadap loyalitas mahasiswa Fakultas Ekonomi Universitas Tadulako menggunakan kosmetik Bedak Marcks di Kota Palu.

D: Apakah variabel pengalaman sosial secara parsial berpengaruh signifikan terhadap loyalitas mahasiswa Fakultas Ekonomi Universitas Tadulako menggunakan kosmetik Bedak Marcks di Kota Palu.

\section{METODE PENELITIAN}

\section{Jenis Penelitian}

Jenis penelitian yang digunakan ialah jenis pendekatan asosiatif. Menurut Sugiyono (2014:55) Penelitian asosiatif merupakan penelitian yang mencari hubungan antara pengalaman konsumen sebagai variabel independen yang terbagi menjadi tiga bagian yaitu: Variabel pengalaman sensori, pengalaman emosional dan pengalaman sosial dan loyalitas mahasiswa Fakultas Ekonomi Universitas Tadulako menggunakan kosmetik Bedak Marcks di Kota Palu sebagai variabel dependen.

Pada jenis penelitian asosiatif ini hubungan variabel yang digunakan ialah hubungan kausal. Hubungan kausal adalah hubungan yang bersifat sebab akibat, dimana variabel pengalaman konsumen mempengaruhi variabel loyalitas mahasiswa Fakultas Ekonomi Universitas Tadulako (Y).

\section{Lokasi Penelitian}

Lokasi penelitian ini dilakukan di Jl. Soekarno Hatta KM. 9 Kampus Bumi Tadulako, Kota Palu. Alasannya berdasarkan masalah yang diangkat oleh penulis bahwa dari observasi awal yang telah 


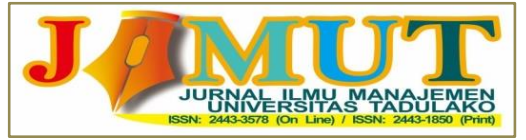

Vol. 7, No 1, Januari 2021, 012-020

dilakukan penulis diketahui beberapa diantara mahasiswa Fakultas Ekonomi Universitas Tadulako telah menjadi konsumen setia kosmetik Bedak Marcks.

\section{Jenis Dan Sumber Data}

Sumber data yang digunakan dalam penelitian ini adalah:

a. Data Primer, adalah data yang didapat langsung dari lapangan. Data primer dalam penelitian ini adalah observasi dan kuesioner dari responden yang terdiri dari mahasiswa Fakultas Ekonomi Universitas Tadulako yang telah loyal dalam menggunakan produk bedak marcks di Kota Palu.

b. Data Sekunder, adalah data informasi yang diperoleh secara tidak langsung dari sumbernya. Berupa jumlah mahasiswa Fakultas Ekonomi Universitas Tadulako yang akan menjadi responden di Kota Palu.

\section{Populasi dan Sampel \\ Populasi}

Menurut Sugiyono (2015:119) "Populasi adalah wilayah generalisasi yang terdiri atas: obyek/subyek yang mempunyai kualitas dan karakteristik tertentu yang ditetapkan oleh peneliti untuk dipelajari dan kemudian ditarik kesimpulan.” Berdasarkan data yang diperoleh dari observasi yang dilakukan sebelumnya oleh peneliti bahwa jumlah mahasiswa aktif di Fakultas Ekonomi Universitas Tadulako berjumlah 4.578 orang. Jumlah tersebut tidak bisa dijadikan populasi karena tidak semua pengguna bedak marcks, dalam artian jumlah populasi tidak diketahui dengan pasti. Maka penelitian ini termasuk dalam kategori non probability sampling.

\section{Sampel}

Karena dalam penelitian ini peneliti tidak mengetahui jumlah populasinya maka digunakanlah pengambilan sampel dengan menggunakan teknik accidental sampling. Accidental Sampling merupakan metode pengambilan sampel yang dilakukan secara kebetulan.

Menentukan besar atau jumlah sampel peneliti merujuk pada teori yang dikembangkan oleh Hair et all (1995 dalam Kiswati 2010) bahwa penentuan jumlah sampel yang representative adalah tergantung pada jumlah indikator dikali 5 sampai 10 . Berdasarkan dari teori Hair et all diatas maka jumlah sampel yang akan diambil dalam penelitian ini adalah sampel $=$ jumlah indikator $\times 5=5 \times 5$ $=75$ responden.

\section{Metode Pengumpulan Data}

Adapun beberapa teknik pengumpulan data, sebagai berikut :

a. Observasi, yaitu peneliti melakukan pengamatan langsung dalam pengumpulan data pada lokasi penelitian yang bertempat di Fakultas Ekonomi Universitas Tadulako.

b. Interview, yaitu peneliti melakukan pengumpulan data melalui wawancara langsung kepada mahasiswa Fakultas Ekonomi Universitas Tadulako.

c. Kuesioner, yaitu peneliti melakukan pengumpulan data melalui beberapa daftar pertanyaan yang disusun secara tertulis dan diajukan kepada mahasiswa Fakultas Ekonomi Universitas Tadulako yang menggunakan produk bedak marcks.

\section{Uji Validitas dan Reliabilitas}

\section{Uji Validitas}

Uji validitas digunakan untuk mengukur sah atau valid tidaknya suatu kuesioner, suatu kuesioner dikatakan valid jika pertanyaan pada kuesioner mampu untuk mengungkapkan sesuatu yang akan diukur oleh kuesioner tersebut. Syarat minimum untuk dianggap memenuhi syarat adalah $r=0.3$.

\section{Uji Realibilitas}

Ghozali (2013:47) uji reliabilitas adalah alat untuk mengukur suatu kuesioner yang merupakan indikator dari variabel atau konstruk. Suatu kuesioner dikatakan reliable atau handal jika jawaban seseorang terhadap pertanyaan adalah konsisten atau stabil dari waktu ke waktu. Pengujian ini 
mengukur sejauh mana reliabelnya suatu variabel dengan cara melihat Cronbach Alpha dengan signifikansi yang digunakan lebih besar dari 0.70 .

\section{Uji Asumsi Klasik}

Masalah-masalah dalam pengujian model regresi dalam penelitian ini dapat menggunakan bentuk model pengujian klasik. Bentuk model pengujian klasik terhadap kenormalan hasil persamaan regresi tersebut dapat dijabarkan sebagai berikut:

\section{Uji Normalitas Data}

Uji normalitas bertujuan untuk mengetahui apakah dalam sebuah model regresi, variabel independen, variabel dependen atau keduanya mempunyai distribusi normal atau tidak. Model regresi yang baik adalah distribusi data normal.

\section{Uji Multikolinieritas}

Uji multikolinieritas berguna untuk mengetahui apakah pada model regresi yang diajukan telah ditemukan korelasi yang kuat antar variabel independen. Jika terjadi korelasi yang kuat, terdapat masalah multikoleniaritas yang harus diatasi (Umar, 2008).

\section{Uji Heterokedastistas}

Uji heterokedastisitas dilakukan untuk mengetahui apakah dalam sebuah model regresi terjadi ketidaksamaan varians dari residual suatu pengamatan ke pengamatan lain (Umar, 2008). Suatu model regresi dikatakan terdeteksi heterokedastisitasnya, apabila diagram pancar residual tidak membentuk pola tertentu.

\section{HASIL DAN PEMBAHASAN}

\section{Hasil Uji Regresi Linear Berganda}

Analisis regresi linier berganda digunakan dalam penelitian ini dengan tujuan untuk membuktikan hipotesis mengenai pengaruh variabel dimensi-dimensi kualitas pelayanan secara parsial maupun secara bersama-sama terhadap kepuasan konsumen. Perhitungan statistik dalam analisis regresi linier berganda yang digunakan dalam penelitian ini adalah dengan menggunakan bantuan program komputer SPSS for Windows versi 21.0

Tabel 5. Hasil Uji Regresi

\begin{tabular}{|l|l|l|l|l|l|}
\hline \multirow{2}{*}{ Model } & \multicolumn{2}{|l|}{$\begin{array}{l}\text { Unstandardized } \\
\text { Cofficients }\end{array}$} & $\begin{array}{l}\text { Standardized } \\
\text { Coefficients }\end{array}$ & \multirow{2}{*}{ t } & Sig \\
\cline { 2 - 4 } & $\mathbf{B}$ & Std. Error & Beta & & \\
\hline (Constant) & 0,055 & 1,252 & & 0.044 & 0,965 \\
\hline $\begin{array}{l}\text { Pengalaman } \\
\text { Sensori }\end{array}$ & 0,129 & 0,055 & 0,102 & 2,368 & 0,020 \\
\hline $\begin{array}{l}\text { Pengalaman } \\
\text { Emosional }\end{array}$ & 1,162 & 0,065 & 0,865 & 17,763 & 0,000 \\
\hline $\begin{array}{l}\text { Pengalaman } \\
\text { Sosial }\end{array}$ & 0,174 & 0,079 & 0,107 & 2,194 & 0,031 \\
\hline $\begin{array}{l}\text { Multiple R }=\mathbf{0 , 9 1 8} \\
\text { Sig. F }=\mathbf{0 , 0 0 0} \\
\text { R Square }=\mathbf{0 , 8 4 2} \\
\text { Adjusted R Square }=\mathbf{0 , 8 3 7}\end{array}$ & & & \\
\hline
\end{tabular}

Sumber: Data diolah sendiri, 2019

Berdasarkan tabel di atas, dapat ditulis dalam bentuk persamaan regresi linear berganda sebagai berikut:

$$
Y=0,055+0,129 \times 1+1,162 \times 2+0,174 \times 3
$$




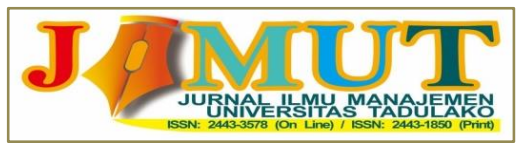

Vol. 7, No 1, Januari 2021, 012-020

Hasil persamaan di atas menunjukan, variabel pengalaman sensori (X1), pengalaman emosional (X2), dan pengalaman sosial (X3) berpengaruh positif terhadap loyalitas mahasiswa Fakultas Ekonomi Universitas Tadulako menggunakan kosmetik Bedak Marcks di Kota Palu.

Tabel di atas menunjukan bahwa nilai sig $\mathrm{F}$ atau probabilitasnya 0.000 yang artinya bahwa jika nilai sig. $\mathrm{F}$ (probability) $\leq \mathrm{a}$ (alpha) $=0,05$, maka dapat diketahui bahwa variabel pengalaman sensori, pengalaman emosional dan pengalaman sosial secara simultan berpengaruh signifikan dengan besar pengaruh $\mathrm{R}$ Square $\left(\mathrm{R}^{2}\right)$ sebesar 0,842 atau $84.2 \%$ terhadap loyalitas mahasiswa Fakultas Ekonomi Universitas Tadulako menggunkan Bedak Marcks di Kota Palu. Sedangkan sisianya $(100 \%-84.2 \%=$ $15.8 \%$ ) dijelaskan oleh sebab-sebab yang diluar dari variabel penelitian ini.

\section{Pengujian Hipotesis}

\section{Hasil Uji F}

Berdasarkan hasil yang diperoleh signifikan $\mathrm{F}$ yaitu 0,000 , artinya nilai tersebut lebih kecil dibandingkan dengan nilai yang disyaratkan yaitu $\alpha=0,05$ dengan tingkat kepercayaan $95 \%$ oleh karena itu, hipotesis diterima.

\section{Hasil Uji t}

Hasil pengujian secara parsial untuk setiap variabel independen terhadap variabel dependen dapat dilihat sebagai berikut:

Variabel Pengalaman Sensori, hasil pengujian diperoleh signifikan t $0,020<0,05$ dengan nilai signifikan di bawah 0,05 tersebut menunjukan bahwa pengalaman sensori memiliki pengaruh yang signifikan terhadap loyalitas mahasiswa Fakultas Ekonomi Universitas Tadulako menggunakan kosmetik Bedak Marcks di Kota Palu. Variabel Pengalaman Emosional, hasil pengujian diperoleh signifikan $\mathrm{t} 0,000<0,05$ dengan nilai signifikan di bawah 0,05 tersebut menunjukan bahwa pengalaman emosional memiliki pengaruh yang signifikan terhadap loyalitas mahasiswa Fakultas Ekonomi Universitas Tadulako menggunakan kosmetik Bedak Marcks di Kota Palu. Variabel Pengalaman Sosial hasil pengujian diperoleh signifikan t $0,031<0,05$, nilai signifikan di bawah 0,05 tersebut menunjukan bahwa pengalaman sosial memiliki pengaruh yang signifikan terhadap loyalitas mahasiswa Fakultas Ekonomi Universitas Tadulako menggunakan kosmetik Bedak Marcks di Kota Palu.

Hasil uji signifikan t pada semua variabel independen dapat disimpulkan bahwa hipotesis dari keseluruhan variabel independen dapat diterima. Artinya semakin baik atau berkesan dalam artian apa yang diharapkan dan diinginkan konsumen dari Bedak Marcks dan juga dari hubungan yang dijalin antara konsumen dan perusahaan dapat terpenuhi dengan baik sesuai apa yang dijanjikan, maka dengan begitu konsumen pun akan merasa puas atau semakin puas, ketika konsumen tersebut puas tebentuklah loyalitas pada konsumen tersebut.

\section{Pembahasan Hasil Penelitian}

Menjalankan bisnis yang dapat memberikan kesan yang baik kepada konsumen merupakan hal yang sangat penting bagi perkembangan suatu perusahaan. Perkembangan usaha industri kosmetik contohnya, semakin meningkatkanya persaingan diindustri kosmetik semakin gencar pula perusahaanperusahaan menciptakan strategi untuk mengembangkan perusahaan mereka. Selain promosi melalui iklan, pemotongan harga, buy one get one dan segala bentuk promosi agar merebut hati pelanggan saat ini juga dengan menciptakan pengalaman bagi konsumen itu adalah hal yang patut dibentuk oleh suatu perusahaan.

\section{Hasil Analisis Secara Simultan}

Hasil dalam penelitian ini menyatakan bahwa pengalaman konsumen yang terdiri dari: pengalaman sensori (X1), pengalaman emosional (X2), dan pengalaman sosial (X3) memiliki pengaruh secara serempak dan signifikan terhadap variabel loyalitas mahasiswa Fakultas Ekonomi Universitas Tadulako menggunakan kosmetik Bedak Marcks di Kota Palu (Y). Hal ini menunjukkan bahwa 
mahasiswa Fakultas Ekonomi Universitas Tadulako memilih menggunakan Bedak Marcks dipengaruhi oleh faktor pengalaman sensori, pengalaman emosional dan pengalaman sosial dengan kata lain jika perusahaan PT. Kimia Farma dapat meningkatkan penciptaan pengalaman bagi para konsumennya maka akan semakin banyak kosnumen yang loyal terhadap kosmetik Bedak Marcks.

\section{Hasil Analisis Secara Parsial}

Adapun untuk mengetahui pengaruh antara variabel independen dan variabel dependen secara masing-masing maka dilakukan uji t. Pengalaman sensori, pengalaman emosional, dan pengalaman sosial memiliki pengaruh positif yang signifikan terhadap loyalitas konsumen.

\section{PENUTUP}

\section{Kesimpulan}

Sesuai dengan penulisan dan pembahasan terhadap perumusan masalah dengan judul yang diangakat mengenai pengaruh pengalaman konsumen terhadap loyalitas mahasiswa Fakultas Ekonomi Universitas Tadulako menggunakan kosmetik Bedak Marcks di Kota Palu maka kesimpulan yang dapat ditarik sebagai berikut:

a. Pengalaman konsumen yang terdiri dari, pengalaman sensori, pengalaman emosional, dan pengalaman sosial secara serempak berpengaruh signifikan terhadap loyalitas mahasiswa Fakultas Ekonomi Universitas Tadulako menggunakan kosmetik Bedak Marcks di Kota Palu.

b. Variabel pengalaman sensori secara parsial berpengaruh signifikan terhadap loyalitas mahasiswa Fakuktas Ekonomi Universitas Tadulako menggunkan kosmetik Bedak Marcks di Kota Palu.

c. Variabel pengalaman emosional secara parsial berpengaruh signifikan terhadap loyalitas mahasiswa Fakultas Ekonomi Universitas Tadulako menggunakan kosmetik Bedak Marcks di Kota Palu.

d. Variabel pengalaman sosial secara parsial berpengaruh signifikan terhadap loyalitas mahasiswa Fakultas Ekonomi Universitas Tadulako menggunakan kosmetik Bedak Marcks di Kota Palu.

\section{Saran}

Hasil penelitian yang dilakukan, maka peneliti dapat memberikan beberapa masukan, antara lain:

a. Karena konsumen sangat tertarik pada kosmetik yang beraroma lembut dan tahan lama maka sebaiknya PT. Kimia Farma harus lebih meningkatkan pengalaman sensori pada konsumen tehadap produk kosmetik Bedak Marcks dengan cara terus meningkatkan detail dalam memberikan aroma yang lembut juga meningkatkan ketahanan make up terkhusus pada wajah konsumen yang cenderung berminyak.

b. Diketahui adanya pengaruh variabel lain diluar model penelitian, oleh karena itu untuk menyempurnakan hasil penelitian ini diharapkan untuk penelitian selanjutnya yang mengambil obyek kosmetik Bedak Marcks, agar menggunakan variabel lain selain variabel sensori, variabel emosional, variabel sosial dan variabel loyalitas.

\section{REFERENSI}

Amin Widjaja Tunggal. 2008. Dasar - Dasar Customer Relationship Management (CRM). Jakarta: Harvindo.

Arnast, Kemal. 2004. Customer Experience Management (CEM) : Jembatan Antara Kepuasan dan Loyalitas.

Ghozali, Imam.2013.Aplikasi Analisis Multivariate dengan program IBM SPSS 19 Semarang : Badan Penerbit Universitas Diponegoro. 


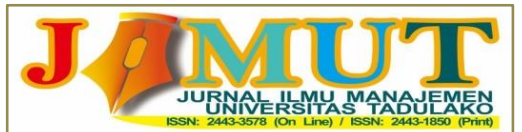

Vol. 7, No 1, Januari 2021, 012-020

Umar, husein. 2008. Metode Penelitian Untuk Skripsi dan Tesis Bisnis. Jakarta. PT Rajagrafindo Persada

Kartajaya, Hermawan. 2004. Marketing In Venus. Jakarta: PT Gramedia

Kartajaya, Hermawan. 2006. Hermawan Kartajaya on Service, seri 9 Elemen Marketing. Bandung: Penerbit Mizan

Kotler, Philip \& Kevin Lane Keller, 2016. Marketing Managemen, 15th Edition, Pearson Education.

Meyer, C., \& Schwager, A. 2007. Understanding customer experience. Harvard Busness Review.

Smilansky, Shaz. 2009. Experiential Marketing: A Practical Guide To Interactive Brand Experiences. London and Philadelphia: Kogan Page.

Sugiyono. (2015). Metode Penelitian Kombinasi (Mix Methods). Bandung: Alfabeta. Cetakan Ke-7

Tiwari, R. S. 2009. Retail management, retail concepts and practices. Mumbai: Himalaya Publishing House.

https://www.promosi247.com/2018/06/kimia-farma-promo-produk-marcks-venus-kosmetik.html 